\title{
Energy efficiency at the building and district levels in a multi-energy context
}

DOI:

10.1109/ENERGYCON.2016.7513928

\section{Document Version}

Accepted author manuscript

Link to publication record in Manchester Research Explorer

\section{Citation for published version (APA):}

Cesena, E. A. M., Good, N., \& Mancarella, P. (2016). Energy efficiency at the building and district levels in a multienergy context. In 2016 IEEE International Energy Conference, ENERGYCON 2016 [7513928] IEEE. https://doi.org/10.1109/ENERGYCON.2016.7513928

\section{Published in:}

2016 IEEE International Energy Conference, ENERGYCON 2016

\section{Citing this paper}

Please note that where the full-text provided on Manchester Research Explorer is the Author Accepted Manuscript or Proof version this may differ from the final Published version. If citing, it is advised that you check and use the publisher's definitive version.

\section{General rights}

Copyright and moral rights for the publications made accessible in the Research Explorer are retained by the authors and/or other copyright owners and it is a condition of accessing publications that users recognise and abide by the legal requirements associated with these rights.

\section{Takedown policy}

If you believe that this document breaches copyright please refer to the University of Manchester's Takedown Procedures [http://man.ac.uk/04Y6Bo] or contact uml.scholarlycommunications@manchester.ac.uk providing relevant details, so we can investigate your claim.

\section{OPEN ACCESS}




\title{
Energy Efficiency at the Building and District Levels in a Multi-Energy Context
}

\author{
E. A. Martínez Ceseña ${ }^{1}$, Nicholas Good ${ }^{2}$ and P. Mancarella ${ }^{3}$ \\ The University of Manchester, School of Electrical and Electronic Engineering \\ Electrical Energy and Power Systems Group \\ Manchester M13 9PL, UK \\ $\left\{{ }^{1}\right.$ eduardo.martinezcesena; ${ }^{2}$ nicholas.good; ${ }^{3}$ p.mancarella $\} @$ manchester.ac.uk
}

\begin{abstract}
Increasing environmental concerns are encouraging new building energy efficiency (EE) concepts defined as reductions in net consumption of electricity, heat, gas and/or other energy vectors. Thanks to the smart grid paradigm, this is increasingly being achieved via the installation of low carbon technologies. However, this approach can be severely limited due to the physical and technical constraints of particular buildings (e.g., limited space to install technologies and limited energy network connection capacity). This paper proposes a more effective approach by explicitly including all relevant multi-energy flows in the EE concept and extending its scope to the district level. This paradigm shift allows energy flows to be produced and consumed in the most effective locations. The benefits from extending the scope of different EE concepts (e.g., based on electricity, electricity and heat, and all vectors) from the building to the district level are illustrated with a real UK multi-energy system.
\end{abstract}

Index Terms-District energy systems, energy efficiency, low carbon technologies, multi-energy systems

\section{INTRODUCTION}

The efficient use of energy resources is currently deemed a key factor to tackle increasing environmental threats by, for example, facilitating a reduction of $\mathrm{CO}_{2}$ emissions. Accordingly, a significant effort has been made to improve energy efficiency (EE) at the building level based on traditional practices that aim at reducing energy waste by, for example, improving the insulation levels of buildings [1], [2]. However, in order to maximise its effectiveness, the EE concept should be extended in light of the emergence of smart solutions at the building (and district) level [3], [4]. These smart solutions include information and communication technologies, and distributed energy resources such as solar photovoltaic (PV) systems, electric heat pumps (EHP), combined heat and power (CHP) and so forth.

In light of the smart grid paradigm, several new building level EE concepts have emerged, such as the net zero energy, nearly zero energy and zero carbon homes [5], [6]. These EE concepts increasingly recognise the smart operation and interactions of energy infrastructure as a means to improve EE. However, some of them neglect the multi-energy properties that are characterising emerging energy systems. In fact, some of these EE concepts only concern a single energy vectors or a limited amount of vectors [6]. Thus, these EE concepts may incentivise high consumption of other energy vectors (e.g., gas); potentially resulting in a decreased environmental performance (e.g., increased $\mathrm{CO}_{2}$ emissions).

Based on the above, literature has proposed the extension the $\mathrm{EE}$ concepts to a multi-energy context that addresses multiple energy vectors [7], [8]. This can be done by either combining the vectors directly or by weighting each vector based on, for instance, its carbon and/or economic content. Nevertheless, the scope of current EE concepts is still limited to the building level. That is, all energy interactions with interconnected energy systems are neglected. This can significantly limit the potential efficiency benefits in each building, particularly if the building does not have the resources to foster and/or accommodate the most attractive technologies (e.g., limited space and network connection capacity).

If the scope of the EE concepts were to be extended to the district level, the operation of energy infrastructure could be optimised to facilitate sharing resources between buildings and further maximise overall efficiency benefits (e.g., $\mathrm{CO}_{2}$ reductions). This may occur as relevant energy flows could be produced more effectively (using the most efficient technologies) and directed to the most attractive locations (e.g., buildings with the worst performance).

In light of the above, this paper aims at providing a proof of concept of the benefits from extending EE concepts to the district level, while explicitly modelling the multi-energy nature of the system (even if not fully addressed by the $\mathrm{EE}$ concept). For this purpose, a methodology is proposed for the assessment and optimisation of multi-energy flows within a building or district. The methodology relies on a mixed integer linear programming (MILP) formulation to optimise multienergy flows based on the needs of either each building or the full district. For the latter, the energy exchanges between buildings are also optimised. The methodology is demonstrated with a real UK system. 
The rest of the paper is structured as follows. Section 2 introduces the proposed methodology for the assessment of EE concepts. The methodology is illustrated with a case study based on real UK buildings in Section III. The main findings are presented in Section IV.

\section{METHODOLOGY}

The proposed methodology has been devised to as sess the effects of different EE concepts at the building or district level. This approach has been customised for multi-energy systems with significant electricity and heat demand, but it can easily be modified to address other systems. The methodology comprises two steps, namely definition of EE concepts and optimisation of the relevant multi-energy flows.

\section{A. Definition of EE concepts}

In light of the discussion presented in the introduction, three EE concepts are selected to illustrate a transition from the use of a single energy vector to all relevant energy vectors [5], [6]. Firstly, EE is defined based only on electricity reductions (compared with a base case) as denoted by (1).

$$
\text { Elec } E=\sum_{t}\left(\text { Ebase }_{t}-E i_{t}^{B}+E o_{t}^{B}\right)
$$

where ElecE represents electricity based $\mathrm{EE}$ concept, Ebase is the base net electricity consumption, $E i$ and $E o$ are the electricity inputs and outputs, the subscript $t$ denotes time (e.g., hours in a year) and the superscript $B$ denotes a parameter estimated at the building level. As with all definitions of $\mathrm{EE}$, this efficiency perspective could be extended to the district level, in which case the supers cript $D$ would be used.

Secondly, the definition of EE is extended to include both heat and electricity, as represented by (2). In this case, the different energy vectors are combined without the use of weights.

$$
\begin{aligned}
\text { EnerE }= & \sum_{t}\left(\text { Ebase }_{t}+\text { Hbase }_{t}-E i_{t}^{B}-H i_{t}^{B}+\right. \\
& \left.+E o_{t}^{B}+H o_{t}^{B}\right)
\end{aligned}
$$

where EnerE denotes energy (electricity and heat) based EE concept, and $H i$ and $H o$ are the heat inputs and outputs, respectively.

Finally, EE is defined in terms of the overall emissions associated with the energy consumption of the building (or district) as denoted by (3). Accordingly, each energy vector has to be weighted based on relevant carbon emis sion factors, which facilitates a reasonable comparison of the different energy vectors.

$$
\mathrm{CO}_{2} E=\sum_{v} \sum_{t} \mathrm{CO}_{2} \text { Vbase }_{t}-\mathrm{CO}_{2} \mathrm{Vi}_{t}^{B}+\mathrm{CO}_{2} \mathrm{Vo}_{t}^{B}
$$

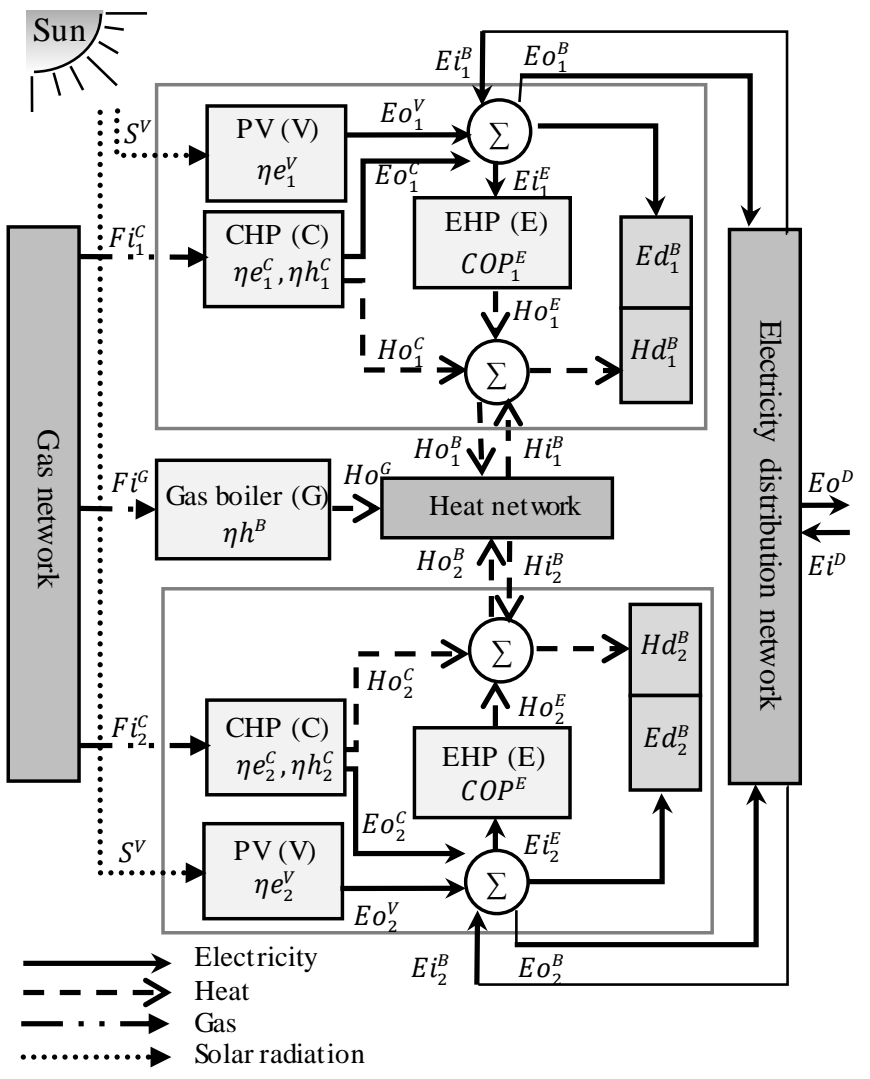

Fig. 1. Flow diagram of the multi-energy system under consideration.

where $\mathrm{CO}_{2} \mathrm{E}$ represents carbon emissions based $\mathrm{EE}$ concept, $\mathrm{CO}_{2}$ Vbase are the emissions as sociated with the use of an energy vector $(v)$ in a base case, and $\mathrm{CO}_{2} \mathrm{Vi}$ and $\mathrm{CO}_{2} \mathrm{Vo}$ are the relevant inputs and outputs.

\section{B. Optimisation model}

A high level flow diagram of the multi energy system under consideration is presented in Fig. 1. For the sake of simplicity, a district with only two buildings is considered in this work. However, the model is generic and can be extended for the consideration of more buildings. It was decided to consider only 2 buildings, as it allows the presentation of most relevant results for each building within this manuscript and, most importantly, suffices to properly highlight the key features of the different EE concepts.

The operation of the multi-energy systems is optimised using the MILP model denoted by (4) - (18). The model was developed based on the flexible formulation presented in [9], [10].

$$
\begin{aligned}
& \text { Minimise: } \\
& \begin{aligned}
C C^{D}= & E F g a s \times \sum_{t}\left(F i_{t}^{G}+\sum_{b} F i_{t}^{C}\right)+ \\
& \sum_{b} \sum_{t}\left[E F \operatorname{Elec}_{t} \times\left(E i_{t}^{D}-E i_{t}^{E}\right)\right]
\end{aligned}
\end{aligned}
$$




$$
\begin{aligned}
& \text { s.t. } \\
& C £^{D}=\sum_{t}\left[P \operatorname{Pas}_{t} \times F i_{t}^{G}+\sum_{b}\left(P £ g a s_{t} \times F i_{t}^{C}+\right.\right. \\
& \mathrm{PEeleci}_{t} \times E i_{t}^{D}-\mathrm{P£eleco} \mathrm{eEo}_{t}^{D}+ \\
& \left.\left.P £ o m^{C} \times E i_{t}^{D}+P £ o m^{E} \times E i_{t}^{E}\right)\right] \\
& H o_{t}^{G}=\eta h^{G} \times F i_{t}^{G} \\
& 0 \leq H o_{t}^{G} \leq \operatorname{Hmax}^{G} \\
& E o_{b, t}^{C}=F i_{b, t}^{C} \times \eta e 1_{b}^{C}+\eta e 2_{b}^{C} \times I_{b, t}^{C} \\
& H o_{b, t}^{C}=F i_{b, t}^{C} \times \eta h 1_{b}^{C}+\eta h 2_{b}^{C} \times I_{b, t}^{C} \\
& -R_{b}^{C} \times d t \leq E o_{b, t}^{C}-E o_{b,(t-1)}^{C} \leq R_{b}^{C} \times d t \\
& I_{b, t}^{C} \times \operatorname{Emin}_{b}^{C} \leq E o_{b, t}^{C} \leq I_{b, t}^{C} \times \operatorname{Emax}_{b}^{C} \\
& H o_{b, t}^{E}=E i_{b, t}^{E} \times C O P_{b}^{E} \\
& 0 \leq H o_{b, t}^{E} \leq \operatorname{Hmax}_{b}^{E} \\
& E o_{b, t}^{V}=S_{t}^{V} \times \operatorname{Emax}_{b}^{V} \times \eta e_{b}^{V} \\
& E d_{b, t}^{B}=E o_{b, t}^{P}+E o_{b, t}^{C}-E i_{b, t}^{E}+E i_{b, t}^{B}-E o_{b, t}^{B} \\
& H d_{b, t}^{B}=H o_{b, t}^{C}+H o_{b, t}^{E}+H i_{b, t}^{B}-H o_{b, t}^{B} \\
& E o_{t}^{D}-E i_{t}^{D}=\sum_{b}\left(E i_{b, t}^{D}-E o_{b, t}^{D}\right) \\
& H o_{t}^{G}=\sum_{b}\left(H i_{t}^{B}-H o_{t}^{B}\right)
\end{aligned}
$$

where $C £$ and $C C$ are the total economic and carbon costs, respectively; $P £ o m, P £ g a s, P £ e l e c i$ and $P £$ eleco are prices associated with operation and maintenance, purchase of gas and purchase and sale of electricity, respectively; EFgas and EFelec are respectively the emission factors for gas and electricity; $E d, E i$ and $E o$ are electricity demand, inputs and outputs, respectively; $\mathrm{Hd}, \mathrm{Hi}$ and $\mathrm{Ho}$ are heat demand, inputs and outputs, respectively; $\eta e$ and $\eta h$ represent electrical and thermal efficiencies (or the components of the efficiency curves); $I$ denotes integervariables needed to model efficiency curves, $C O P$ is the coefficient of performance, $S$ is the solar radiation, $F i$ denotes fuel (gas) inputs, Hmax represents limits in the maximum heat output; Emin and Emax are respectively minimum and maximum electricity outputs and $R$ denotes ramping constraints.

It is worth noting that the subscripts $t$ and $b$ are used to denote time steps and particular buildings, respectively. The superscripts $C, E, G$ and $V$ are used to represent parameters associated with CHP, EHP, gas boilers and PV systems, respectively. The superscripts $B$ and $D$ are used to denote parameters for entire buildings and the whole district, respectively.

The objective function, denoted by (4), aims at minimising $\mathrm{CO}_{2}$ emissions from gas and electricity consumption. As presented in (5), overall costs include gas and electricity import costs, and operation and maintenance costs (investment costs are not considered). As a summary, the operation and limits of the gas boiler are modelled with (6) and (7), respectively. The electrical operation and thermal operation of the CHPs are modelled with (8) and (9). The relevant ramping and capacity limits are denoted by (10) and (11), respectively. The operation of the EHPs is represented with (12) and its limits are modelled with (13). The PV systems are modelled with (14). Electricity and heat balance are imposed at the building level with (15) and (16), respectively. Electricity and heat balance are imposed at the district level with (17) and (18), respectively.

The full formulation presented above is used to model the operation of the systemwhen optimised at the district level. At the building level, the model is used to optimise the operation of each building (one at a time). Afterwards, the outputs are combined to recalculate the emissions and relevant economic costs with (4) and (5). All savings due to reduced inputs or increased exports are apportioned to each building proportionally to their imports and exports.

\section{CASE STUDY}

In this section, the benefits from extending the scope of different EE concept from the building to the district level are illustrated with a case study based on real UK buildings. The buildings under consideration are the Christie and Coupland buildings owned by The University of Manchester. Both buildings are connected to the same electricity distribution, heat and gas networks. Currently, electricity is mainly generated off-campus and sold to the university by retailers. Heat, on the other hand, is produced centrally on-campus by large gas boilers, which supply the heat network.

Based on current environmental targets, the university is planning to improve the EE of existing university owned buildings. Accordingly, in this example, it is assumed that the efficiency of the aforementioned buildings is to be improved by $10 \%$ based on the different EE concepts (a specific multienergy system design is developed for each EE concept). For this purpose, and based on the technologies preferred by the university, it is possible to install PV panels and EHP units in the buildings to meet the EE targets. In addition, in this example, the use of CHP units, which are highly flexible multi-energy devices, is also considered.

It is assumed that the efficiency of the gas boilers and PV panels is $85 \%$ and $17 \%$, respectively. A coefficient of performance of 3 is considered for the EHP units. The electrical and heat efficiencies of the CHP units are assumed to be $35 \%$ and $45 \%$, respectively [10]. The buildings are modelled based on their half-hourly electricity, heat and gas consumption during 2014 [11]. The corresponding dynamic prices and carbon intensities associated with the use of the electricity and gas networks in the UK were taken from the disaggregated price models presented in [12], [13].

Four cases are considered to illustrate a baseline and three different single/multi EE concepts:

1. Base case: This case is used as a baseline, as it represents the current conditions of the buildings where no energy infrastructure has been installed. 
2. Electricity efficiency(ElecE) case: This case represents a single-vector EE concept. More specifically, in this case, energy infrastructure is placed to improve efficiency in terms of electricity consumption reductions.

3. Energyefficiency (EnerE) case: This case extends the EE concept to multi-energy systems by considering two vectors, namely electricity and heat.

4. Carbon efficiency $\left(\mathrm{CO}_{2} \mathrm{E}\right)$ case: This case further extends the EE concept by considering all relevant energy vectors and expressing efficiency in $\mathrm{CO}_{2}$ terms .

In addition to $\mathrm{EE}$ concept cases, three operation regimes for the energy infrastructure in each building are considered. These regimes highlight a transition from current building level operation practices to smarter operational practices with a dis trict level scope:

a) Traditional: Based on current practices, the EHP and CHP units are operated in heat following mode based on heat demand at the building level.

b) Optimised at the building level: The traditional operation is enhanced by considering smart control and communication infrastructure. More specifically, the operation of relevant energy infrastructure is optimised to minimise $\mathrm{CO}_{2}$ emissions at the building level.

c) Optimised at the district level: The operation of relevant infrastructure is further enhanced in light of potential multi-energy flows between buildings. That is, the infrastructure in each building is operated to minimise overall $\mathrm{CO}_{2}$ emissions at the district level.

\section{A. System design}

Now that the EE concepts have been defined, the next step is to select relevant infrastructure to improve the performance of each building (i.e., four designs are considered for each building). For this purpose, a basic heuristic approach based on a priority list is used. More specifically, a list of technologies with different priorities is defined for relevant energy vectors based on current planning preferences at the university (i.e., PV followed by CHP for electricity generation and EHP followed by CHP for heat production). In addition, the capacity limits for each technology are selected based on the specific characteristics of each building as detailed below. It is worth highlighting that the technologies are sized using a heuristic search (bis ection method [14]).

The Coupland building is currently used for teaching and research activities and has an annual electricity and heat demand of $225 \mathrm{MWh}$ (97 kW peak) and $734 \mathrm{MWh}(738 \mathrm{~kW}$ peak), respectively (Base case). Based on the available space (in the rooftop and nearby areas), it is assumed that the building could accommodate a PV system of up to $40 \mathrm{~kW}$. Taking into account the firm capacity of the electricity feeder supplying the building, it is possible to install up to $40 \mathrm{~kW}$ of EHP capacity. In addition, it is also possible to install $10 \mathrm{~kW}$ of CHP capacity.

As shown in Table I, the installation of a $25 \mathrm{~kW}$ PV system would allow a reduction in net electricity consumption of roughly $10 \%$ (ElecE case). In order to reduce the net electricity and heat consumption of the building (EnerE case) by at least $10 \%$ ( $12 \%$ in this case), it is required to install 30 $\mathrm{kW}$ and $40 \mathrm{~kW}$ of PV and EHP capacity, respectively. Finally, in order to reduce emissions by roughly $10 \%\left(\mathrm{CO}_{2} \mathrm{E}\right.$ case $) 10$ $\mathrm{kW}$ of CHP capacity have to be installed, as well as $30 \mathrm{~kW}$ and $40 \mathrm{~kW}$ of PV and EHP capacity, respectively.

The Christie building is currently used as a library and restaurant and has an annual electricity and heat demand of $181 \mathrm{MWh}$ (73 kW peak) and $166 \mathrm{MWh}$ (290 kW peak), respectively (Base case). It is assumed that the building could host up to $30 \mathrm{~kW}$ and $10 \mathrm{~kW}$ of PV and EHP capacity, respectively.

As shown in Table II, an improvement in electricity efficiency (ElecE case) of 10\% can be achieved after installing $20 \mathrm{~kW}$ of PV capacity. The electricity and heat efficiency target (EnerE case) could be met by installing $20 \mathrm{~kW}$ and 10 $\mathrm{kW}$ of PV and EHP capacity, whereas the $\mathrm{CO}_{2}$ efficiency target $\left(\mathrm{CO}_{2} \mathrm{E}\right.$ case $)$ can be achieved by installing $30 \mathrm{~kW}$ of PV capacity.

It is worth noting that assessments of investment costs in underlying energy infrastructure are considered beyond the scope of this work. This allows the study to focus on the operational benefits/costs from increasing the scope of different EE concepts to the district level (without investing in additional infrastructure).

\section{B. Traditional operation (building level)}

Table III presents the energy performance of the buildings (in terms of $\mathrm{CO}_{2}$ and economic costs) when operating relevant infrastructure in the traditional heat following mode.

T ABLE I. OPTIONS TO MEET THEENERGY REDUCTION TARGET IN THE COUPLAND BUILDING BASED ON DIFFERENT EE CONCEPTS

\begin{tabular}{|l|l|l|l|ll|ll|}
\hline \multirow{2}{*}{ Case } & \multicolumn{2}{|l|}{ Capacity (kW) } & \multicolumn{2}{|l|}{ Electricity } & \multicolumn{2}{l|}{ Heat and elec. } \\
\cline { 2 - 8 } & PV & EHP & CHP & \multicolumn{2}{|l|}{$(\mathbf{k W h} / \mathbf{y})$} & \multicolumn{2}{l|}{$(\mathbf{k W h} / \mathbf{y})$} \\
\hline Base & 0 & 0 & 0 & 225 & $(100 \%)$ & 959 & $(100 \%)$ \\
\hline ElecE & 25 & 0 & 0 & 203 & $(90 \%)$ & 938 & $(98 \%)$ \\
\hline EnerE & 30 & 40 & 0 & 242 & $(108 \%)$ & 847 & $(88 \%)$ \\
\hline $\mathrm{CO}_{2} \mathrm{E}$ & 30 & 40 & 10 & 209 & $(93 \%)$ & 776 & $(81 \%)$ \\
\hline
\end{tabular}

T ABLE II. OPTIONS TO MEET THEENERGY REDUCTION TARGET IN THE CHRISTIE BUILDING BASED ON DIFFERENT EE CONCEPTS

\begin{tabular}{|c|c|c|c|c|c|c|c|}
\hline \multirow[t]{2}{*}{ Case } & \multicolumn{3}{|c|}{ Capacity (kW) } & \multirow{2}{*}{\multicolumn{2}{|c|}{$\begin{array}{l}\text { Eectricity } \\
(\text { kWh/y) }\end{array}$}} & \multirow{2}{*}{\multicolumn{2}{|c|}{$\begin{array}{l}\text { Heat and elec. } \\
(k W h / y)\end{array}$}} \\
\hline & PV & EHP & CHP & & & & \\
\hline Base & 0 & 0 & 0 & 181 & $(100 \%)$ & 347 & $(100 \%)$ \\
\hline ElecE & 20 & 0 & 0 & 164 & $(90 \%)$ & 330 & $(95 \%)$ \\
\hline EnerE & 20 & 10 & 0 & 179 & $(99 \%)$ & 299 & $(86 \%)$ \\
\hline $\mathrm{CO}_{2} \mathrm{E}$ & 30 & 0 & 0 & 155 & $(86 \%)$ & 321 & $(92 \%)$ \\
\hline
\end{tabular}

T ABLE III EMISSIONS AND COSTS ATTRIBUTED TO THE SYSTEMS WHEN OPERATED IN THE TRADITIONAL (HEAT-FOLLOWING) MODE

\begin{tabular}{|c|c|c|c|c|c|c|c|c|}
\hline \multirow[t]{2}{*}{ Case } & \multicolumn{4}{|c|}{ Coupland } & \multicolumn{4}{|c|}{ Christie } \\
\hline & \multicolumn{2}{|c|}{$\mathrm{CO}_{2}\left(\mathrm{tCO}_{2} / \mathrm{y}\right)$} & \multicolumn{2}{|c|}{$\operatorname{Cost}(\mathbf{k} f)$} & \multicolumn{2}{|c|}{$\mathrm{CO}_{2}\left(\mathrm{tCO}_{2} / \mathrm{y}\right)$} & \multicolumn{2}{|c|}{ Cost $(k £)$} \\
\hline Base & 289 & $(100 \%)$ & & $(100 \%)$ & 138 & $(100 \%)$ & 25 & $(100 \%)$ \\
\hline ElecE & 277 & $(96 \%)$ & 51 & $(97 \%)$ & 129 & $(93 \%)$ & 24 & $(94 \%)$ \\
\hline EnerE & 271 & $(94 \%)$ & 49 & $(93 \%)$ & 127 & $(92 \%)$ & 23 & $(93 \%)$ \\
\hline $\mathrm{CO}_{2} \mathrm{E}$ & 260 & $(90 \%)$ & 48 & $(91 \%)$ & 124 & $(90 \%)$ & 23 & $(91 \%)$ \\
\hline
\end{tabular}


The results highlight that, as expected, the environmental effectiveness of using a single energy vector for the assessment of EE can vary substantially. For example, a $10 \%$ electricity reduction (ElecE case) only results in a $4 \%$ carbon reduction in the Coupland building, as this building is more dependent on heat than on electricity. Conversely, emissions are reduced by a significant $7 \%$ in the Christie building, which is highly dependent on electricity. This variation in the carbon content is a clear disadvantage of EE concepts defined by a single energy vector.

The consideration of several energy vectors as part of the EE concept (EnerE case) provides more attractive results. In this case, carbon emissions decreased by $6 \%$ and $8 \%$ in the Coupland and Christie buildings, respectively. However, the $10 \%$ carbon reduction target is not reached in this case as this EE concept still does not address all relevant vectors.

In the $\mathrm{CO}_{2} \mathrm{E}$ case, all relevant energy vectors are considered to explicitly meet the carbon target. This case generally recommends the installation of more infrastructure than that recommended in previous cases. This provides further evidence that $\mathrm{EE}$ concepts that do not explicitly consider all relevant multi-energy vectors may underestimate efficiency needs.

The results in Table III also highlight that, evidently, the annual operational costs are reduced when electricity and heat consumption is reduced, which could motivate investments in additional infrastructure. However, the analysis of this hypothesis is beyond the scope of the work, as it would require significant discussion on cost benefit analysis and investment optimisation (under uncertainty). Research on investments is left for future work.

\section{Optimised operation (building level)}

Some of the energy system designs presented above include EHP and CHP units, which are controllable devices. These devices add flexibility to the energy systems to customise or even optimise their energy production [9]. In this subsection, the energy systems in each EEcase are optimised with the aim of reducing $\mathrm{CO}_{2}$ emissions within the respective building (without considering impacts on economic costs). The results are presented in Table IV.

As expected, the use of optimised strategies is not attractive for the Base case, as there is no controllable infrastructure to optimise. This is also the case for inflexible system designs, such as the one associated with the ElecE cases in both buildings.

The optimisation of the operational regime of the energy systems at the building level provides modest carbon benefits and can even result in increased costs compared with traditional operation. For example, in most cases, the carbon benefits from optimising the EnerE and $\mathrm{CO}_{2} \mathrm{E}$ systems at the building level are not even noticeable in the table (i.e., less than $0.5 \%$ ), whereas their as sociated costs can be significant (i.e., more than 6\%). Only the $\mathrm{CO}_{2} \mathrm{E}$ case in the Coupland building produced discernible benefits $\left(0.95 \% \mathrm{CO}_{2}\right.$ reduction) due to the availability of a flexible $10 \mathrm{~kW}$ CHP unit. However, even in this case, costs increased significantly (by 5.55\%) when the system was optimised.
These results highlight that the flexibility and resources of energy systems at the building level can be too limited in some cases. In fact, based on these results, most rational building managers would prefer traditional operations over optimised ones. However, as presented below, the flexibility of the systems and relevant benefits can increase substantially when extending the scope of the EE concept to the district level.

\section{Optimised operation (district leve)}

The use of the district level scope allows the consideration of multi-energy exchanges between buildings. This is possible in this example because both buildings are connected to the same electricity and heat networks. Accordingly, the operation of the energy systems in each building can be coupled, effectively increasing the flexibility of the system. Table V shows the performance of the systems in each building when optimised at the district level to minimise the aggregated $\mathrm{CO}_{2}$ emissions.

It can be seen that, even when coupled, the systems in the Base and ElecE cases do not improve their performance, compared to the building level optimisation. This occurs because there are no controllable devices in either building in these cases.

The flexible EHP capacity $(40 \mathrm{~kW})$ available in the EnerE cases allows a small reduction in the aggregated carbon emissions at the expense of increasing costs. The aggregated carbon and economic costs are presented in Table VI and Table VII, respectively. These results are similar to those when the systems were optimised at the building level, with the difference that now the Christie building is supporting the Coupland building. That is, the performance of the Christie building is worsened (i.e., costs increase) to facilitate greater $\mathrm{CO}_{2}$ reductions in the Coupland building (and the overall district). These results illustrate two key points. Firstly, the benefits from aggregating buildings at the district level may not be significant if the underlying energy systems have little flexibility and are similar (i.e., both systems are based on PV and EHP technologies). This should become less of an issue in

TABLE IV EMISSIONS AND COSTS ATTRIBUTED TO THE ENERGY SYSTEMS WHEN OPTIMISED AT THE BUILDING LEVEL

\begin{tabular}{|c|c|c|c|c|c|}
\hline \multirow[t]{2}{*}{ Case } & \multicolumn{2}{|l|}{ Coupland } & \multicolumn{3}{|c|}{ Christie } \\
\hline & $\mathrm{CO}_{2}\left(\mathrm{tCO}_{2} / \mathrm{y}\right)$ & Cost $(k £)$ & $\mathrm{CO}$ & $\left.\mathrm{tCO}_{2} / \mathrm{y}\right)$ & Cost (kf) \\
\hline Base & $289 \quad(100 \%)$ & $53 \quad(100 \%)$ & 138 & $(100 \%)$ & $25 \quad(100 \%)$ \\
\hline ElecE & $(96 \%)$ & $(97 \%)$ & 129 & $(93 \%)$ & $(94 \%)$ \\
\hline EnerE & $(94 \%)$ & $(97 \%)$ & 127 & $(92 \%)$ & $(99 \%)$ \\
\hline $\mathrm{CO}_{2} \mathrm{E}$ & $(89 \%)$ & $(96 \%)$ & 124 & $(90 \%)$ & $(97 \%)$ \\
\hline
\end{tabular}

TABLE V EMISSIONS AND COSTS ATTRIBUTED TO THE ENERGY SYSTEMS WHEN OPTIMISED AT THE DISTRICT LEVEL

\begin{tabular}{|c|c|c|c|c|c|c|c|}
\hline \multirow[t]{2}{*}{ Case } & \multicolumn{4}{|c|}{ Coupland } & \multicolumn{3}{|c|}{ Christie } \\
\hline & \multicolumn{2}{|c|}{$\mathrm{CO}_{2}\left(\mathrm{tCO}_{2} / \mathrm{y}\right)$} & \multicolumn{2}{|c|}{ Cost $(k £)$} & \multicolumn{2}{|c|}{$\mathrm{CO}_{2}\left(\mathrm{tCO}_{2} / \mathrm{y}\right)$} & Cost $(k £)$ \\
\hline Base & 289 & $(100 \%)$ & 53 & $(100 \%)$ & 138 & $(100 \%)$ & $25 \quad(100 \%)$ \\
\hline ElecE & 277 & $(96 \%)$ & 51 & $(97 \%)$ & 129 & $(93 \%)$ & $(94 \%)$ \\
\hline EnerE & 269 & $(93 \%)$ & 52 & $(99 \%)$ & 127 & $(92 \%)$ & $26 \quad(105 \%)$ \\
\hline $\mathrm{CO}_{2} \mathrm{E}$ & 256 & $(88 \%)$ & 50 & $(95 \%)$ & 105 & $(76 \%)$ & $(90 \%)$ \\
\hline
\end{tabular}


districts with several buildings that are likely to have a wide variety of technologies. Secondly, the performance of particular buildings may be worsened if it facilitates overall improvements throughout the district. This is not an issue if both buildings are owned by the same entity, as in this example. However, if the buildings are owned by different actors, a compensation scheme would have to be introduced to reward the owners of those buildings whose performance is affected.

The energy systems in the $\mathrm{CO}_{2} \mathrm{E}$ case couple two flexible technologies, namely EHP $(30 \mathrm{~kW})$ and CHP $(10 \mathrm{~kW})$. This facilitates significant improvements in the performance of the buildings, particularly in the Christie building. This time, the Coupland building is maximising the use of the CHP unit to export electricity and heat flows to the Christie building, while supplying own demand. As a result, the Coupland building reduces its carbon emissions at the expense of increasing its costs, while also facilitating an attractive reduction in both carbon emissions and costs in the Christie building. This provides further evidence that (i) the performance of some buildings may be compromised to improve the overall performance of the district and (ii) the availability of different flexible technologies can significantly improve the efficiency of the district, which is not the case when optimising the system at the building level.

\section{CONCLUSION}

This paper provided an assessment of the benefits from extending the scope of different EE concept (based on a single or multiple energy vectors) from the building to the district levels. For this purpose, the $\mathrm{CO}_{2}$ and economic costs associated with energy systems devised according to $\mathrm{EE}$ concepts based on a single energy vector, two vectors and all relevant vectors were studied using a real UK study. In addition, each energy system was as sessed in light of current building level heat-following operations, and novel operation regimes optimised at the building and district levels.

The results demonstrate that the use of EE concepts based on a single energy vector (e.g., electricity) may be misleading, as it can undermine the impacts of other energy vectors. A full multi-energy approach that maps all relevant energy vectors is likely to produce better results in terms of $\mathrm{CO}_{2}$ savings (or economic costs if that were the objective function).

It was also highlighted that the use of a building level approach for the assessment of efficiency can be deemed adequate for inflexible systems with little or no controllable energy technologies (e.g., buildings with only PV panels). However, in light of flexible systems (e.g., with CHP) which are emerging alongside smart technologies, the use of a district level scope can provide attractive carbon savings compared to the building level optimis ation.

\section{ACKNOWLEDGMENT}

The authors are grateful for the inputs provided by all partners in the DIMMER project, particularly Mark Anderson, Richard Mizzi and Eddie Waldron from Arup, as well as to the European commission for the economic support under grant 609084.
T ABLE VI. AGGREGATED EMISSIONS ATTRIBUTED TO BOTH BUILDINGS BASED ON THE DIFFERENT EE CONCEPTS

\begin{tabular}{|l|cl|rl|rl|}
\hline \multirow{2}{*}{ Case } & \multicolumn{2}{|c|}{$\mathbf{C O}_{2}(\mathbf{t C O} / \mathbf{y})$} & \multicolumn{4}{l|}{} \\
\cline { 2 - 7 } & \multicolumn{2}{|c|}{ Traditional } & \multicolumn{2}{|c|}{ Optimised (building) } & \multicolumn{2}{|c|}{ Optimised (district) } \\
\hline Base & 427 & $(100 \%)$ & 427 & $(100 \%)$ & 427 & $(100 \%)$ \\
\hline ElecE & 406 & $(95 \%)$ & 406 & $(95 \%)$ & 406 & $(95 \%)$ \\
\hline EnerE & 398 & $(93 \%)$ & 398 & $(93 \%)$ & 396 & $(93 \%)$ \\
\hline CO2E & 384 & $(90 \%)$ & 381 & $(89 \%)$ & 361 & $(84 \%)$ \\
\hline
\end{tabular}

TABLE VII. AGGREGATED COSTS ATTRIBUTED TO BOTH BUILDINGS BASED ON THE DIFFERENT EE CONCEPTS

\begin{tabular}{|l|cc|ll|ll|}
\hline \multirow{2}{*}{ Case } & \multicolumn{2}{|l|}{$\mathbf{C O}_{2}\left(\mathbf{t C O}_{2} / \mathbf{y}\right)$} \\
\cline { 2 - 7 } & \multicolumn{2}{|c|}{ Traditional } & \multicolumn{2}{l|}{ Optimised (building) } & \multicolumn{2}{|l|}{ Optimised (district) } \\
\hline Base & 78 & $(100 \%)$ & 78 & $(100 \%)$ & 78 & $(100 \%)$ \\
\hline ElecE & 74 & $(96 \%)$ & 74 & $(96 \%)$ & 74 & $(96 \%)$ \\
\hline EnerE & 72 & $(93 \%)$ & 76 & $(98 \%)$ & 78 & $(101 \%)$ \\
\hline $\mathrm{CO}_{2} \mathrm{E}$ & 71 & $(91 \%)$ & 75 & $(97 \%)$ & 73 & $(93 \%)$ \\
\hline
\end{tabular}

\section{REFERENCES}

[1] R. Ruparathna, K. Hewage and R. Sadiq, "Improving the energy efficiency of the existing building stock: A critical review of commercial and institutional buildings," Renewable and Sustainable Energy Reviews, vol. 53, pp. $1-14,2016$.

[2] F. Ardente, M. Beccali, M. Cellura and M. Mistretta, "Energy and environmental benefits in public buildings as a result of retrofit actions," Renewable and Sustainable Energy Reviews, vol. 15, pp. 460 $-470,2011$.

[3] P. Mancarella, "MES (multi-energy systems): An overview of concepts and evaluation models," Energy, vol. 65, pp. 1 -17, 2014.

[4] M. Beccali, "Energy retrofit of a single-family house: Life cycle net energy saving and environmental benefits," Renewable and Sustainable Energy Reviews, vol 27, pp. 283 -293, 2013.

[5] A.J. Marszal and P. Heiselberg, "A Literature Review on ZEB Definitions," Department of civil engineering, Aalborg University, Denmark, Tech. Rep. DCE-78, Dec. 2009.

[6] I. Sartori, A. Napolitano and K. Voss, "Net zero energy buildings: A consistent definition framework," Energy and Buildings, vol. 48, pp. $220-232,2012$.

[7] A. J. Marszal, P. Heiselberg, J. Bourrelle, E. Musall, K. Voss, I. Sartori and A. Napolitano, "Zero Energy Building-A review of definitions and calculation methodologies," Energy and Buildings, vol. 43, pp. 971 979, 2011

[8] P. Stoll, N. Brandt, and L. Nordström, "Including dynamic CO2 intensity with demand response," Energy Policy, vol. 65, pp. 490 -500, 2014.

[9] T. Capuder and P. Mancarella, Techno-economic and environmental modelling and optimization of flexible distributed multi-generation options, Energy, vol. 71, pp. 516-533, 2014.

[10] E. A. Martinez Cesena, T. Capuder and P. Mancarella, "Flexible Distributed Multienergy Generation System Expansion Planning Under Uncertainty," IEEE Transactions on Smart Grid, in press.

[11] Coherent Research Ltd, 2015. [Online]. Available: https://www.ems.estates.manchester.ac.uk/DCS/Logon.aspx ?ReturnUrl=\%2fDCS. [Accessed: 19 - Nov.- 2015].

[12] DECC, "Fuel Mix Disclosure data table," 2012. [Online]. Available: http://www.decc.gov.uk/en/content/cms/statistics/energy_stats/fuel_mi x/fuel_mix.aspx. [Accessed: 19 - Nov.- 2015].

[13] N. Good, E. A. Martínez Ceseña, L. Zhang and P. Mancarella, "Technoeconomic and business case assessment of low carbon technologies in distributed multi-energy systems," Applied Energy, in press.

[14] T. H. Cormen, C. E. Leiserson, R. L. Rivest, and C. Stein, Introduction to Algorithms, 2nd ed. McGraw-Hill Science/Engineering/Math, Dec.2003. 